\title{
Online Customer Comments and their Impact on Consumer Buying Behavior: Using Social Cognitive Theory to Understand Consumer Expectations and Media Influences
}

\author{
Ravikumar. J.S, Syed Mohammad Ghouse, T. Narayana Reddy
}

\begin{abstract}
Many opportunities, with the help of web-based technologies, are provided to word-of-mouth communication. The method of communication of customers and sharing the product details with others is transformed by the immense utilisation of electronic commerce shopping communities. Until recently, the area of e-commerce shopping communities where buyers participate has been underexplored in the field of academic research. The online reviews provided by the customers exert a high impact on customers' buying decisions while shopping on e-commerce websites and thus provides significance to the concept of word of mouth. The growing amount of literature covering various domains that emphasizes customers' reviews online can be considered as a justification of this concept. The factors that affect continual intention of buying online and the extent, reciprocity and reputation of vendor creativity affect consumer expectations. This study provides a brief insight into online customer reviews and their impact on consumer buying behavior by using social cognitive theory. A conceptual framework showcasing the various factors affecting the perceptions and attitudes of consumers in the context of online reviews will be provided in the paper. This study is the first to apply social cognitive theory on online customer reviews and to study their impact on consumer expectations.
\end{abstract}

Keywords : Customer reviews, customer behavior, social cognitive theory, customer expectations.

\section{INTRODUCTION}

\section{RESEARCH BACKGROUND}

A range of internet-based information sources like blogs, social media, and online rating and survey sites are present on the Web. Some of the examples of these websites are YouTube.com, Eopinion.com, Amazon.com and consumerreview.com which offers opinions, ratings and reviews. In addition to these credible sources, the utilization of these internet-based sites by the customers also influences consumers' determination to purchase products and services. The data which is gathered from the review sites is preferably

Revised Manuscript Received on September 22, 2019.

* Correspondence Author

Ravikumar .J.S, Research Scholar, Department of Management, Jawaharlal Nehru Technological University, Ananthapuramu, Andhra Pradesh, India.

Dr.Syed Mohammad Ghouse, Associate Professor, Department of Management, Presidency University, Bangalore, Karnataka, India

Dr. T. Narayana Reddy, Associate Professor, Department of Management, Jawaharlal Nehru Technological University, Ananthapuramu, Andhra Pradesh, India given more importance by the usual visitors and regular visitors of online survey websites or communities of virtual shopping as compared to the casual visitors that rarely use the review sites. The studies carried out by the Industry highlight that presently online review sites are rapidly growing. The resultant effect on purchasing behaviour has yet to be established. Recipients' perspective in the context has been explored by a few studies. Services do not have return policies or the ones like to try before you buy. In such cases, word of mouth becomes extremely valuable. Bansal and Voyer, (2000) and Ekelund et al. (1995) estimated that owing to the heterogeneous nature of service quality in marketing services, the risk factor and the impalpable nature of the services are higher. , A vital role is played by WOM in service marketing. Senecal and Nantel (2004), in their studies, demonstrated that customers nowadays are relying particularly on online reviews that enable them to access services preceding their purchase. Sites such as Yelp.com, TripAdvisor.com and City-Search.com are in of high demand. Such websites specifically focus on various services. Corresponding studies by Wangenheim and Bayon (2004) shows that the efficacy of interpersonal impact relies on the specific characteristics of evaluation by consumers. Consumers take a higher risk with their uncertain knowledge while buying services, and it diversifies across a range of category of services. Resultantly, credence services that are evaluated by the consumers have more probability of emphasizing specific features of the reviews as compared to others. However, as described by Liang and Lai (2000), the online shopping behavior comprises of five steps, that are relevant to traditional shopping behavior.

\section{Study Objectives:}

- To evaluate the influence of customer buying behavior

- To investigate the effect of online customer reviews on buying behavior.

- To understand the social cognitive theory and its applicability in the current study.

- To assess the interrelationship between online customer reviews and customer buying behaviour 


\section{EXPLORING OF CLOUD ACCOUNTING}

\subsection{ONLINE REVIEWS AND CONSUMER LEARNING}

Liang and Lai (2000) depict buying services or products using the Internet as online shopping behavior (likewise called online purchasing behavior). Broad investigations of online shopping behavior and attitudes have been recently conducted. The major part of the studies has made an effort to perceive the factors adding to and impacting shopping attitude of the customer. In an online survey which includes 425 MBA students and undergraduate students from U.S., Case, Burns, and Dick (2001), recommend that knowledge of internet, level of education and information about income are potential predictors of online purchasing patterns. Ho and Wu (1999) recognized the optimistic relationship between the online shopping behavior of the consumers and the five elements, particularly, quality of the product, e-stores' logistical support, website's technological characteristics, display of homepage and characteristics of information. (Arndt 1967) realized the importance of knowledge acquisition and learning regarding decision-making processes of customers in the dynamics of online shopping field. While shopping online, users share information, rely upon the thoughts and opinions of other users, influence each other's ideologies and communicate with each other (Centola 2010). More specifically, the information is operationalized as product information prescribed by various risks related to products and the intention as the purchase intentions of consumers. In the world of online shopping, particularly of experience products, the quality reviews that a product receives are significant. New product sales are significantly influenced by online reviews. As suggested by Cui et al., (2012) the impact of the reviews inclines to be firm or poor that relies upon the category of the product. These investigations have significantly enhanced our understanding of the effect of online reviews on customer learning. However, the rational comprehension of important factors affecting online shopping behavior and attitudinal patterns is lacking. An antithetical classification and recognition of significant independent and dependent variables compare different studies as the applications of current research findings are limited.

\subsection{ONLINE REVIEWS, SOCIAL COGNITIVE THEORY AND CONSUMER BEHAVIOR:}

Significant curiosity and consideration have been obtained by a moderately novel form of online social interaction from the customers worldwide. Chen et al., (2010) disclosed that the major part of online social buyers' communities comprise of advanced options and interactive features which allows customers to notice the behavior of other users as well to receive feedback and appraisal from others. The reviews of online shopping communities related to the participation of customers can be elucidated through various processes such as social learning. Social Cognitive Learning Theory clarifies human conduct from the perspective of a constant and persistent reciprocal interaction among cognitive, environmental, and behavioural determinants. The social cognitive theory described by Bandura (1997) suggested two variants of social learning processes, which are observational learning also referred to as OL and reinforcement learning which can also be called as RL. Observational learning is the manner in which people notice other's behavior and conduct by learning. To dodge needles and costly errors, individuals participate in particular behavior by observing others is referred to as observational learning. Reinforcement accentuates that individual's gain from the outcomes of their behavior. In this case, individuals tend to enhance or diminish the frequency of behavior that results in either constructive or destructive consequences (Bandura, 2001). Some of the studies have employed the theory to elaborate customer behavior in context to information contribution in online social communities. However, a major part of the studies conducted in this domain only investigated the responsibility of Observational learning and reinforced learning on the behavior of customers in online social communities. Chen, Wang, and Xie (2011) carried out a study to compare the effect of E-WOM and Observational Learning on Amazon's sales. Impact of knowledge and self-learning efficiency on customers and their knowledge-sharing attitude was elaborated by Cheung and Lee (2012). According to Bandura (1997, 2001), Observational learning takes place when individuals notice the actions of other individuals and settle on the same choices that other individuals have settled on. Further, Simpson, Siguaw, and Cadogan (2008) reported that purchase decisions of people are influenced by their observation of the purchasing behavior of other individuals. Wiesenfeld, Raghuram, and Garud (1999) argued that the virtuous learning cycle is created by Positive reinforcement. Many social platforms and communities allow the members to input feedback and appraisal on posts and reviews of other people. For instance, feedbacks or remarks can be provided on other's posts. This attribute, as such improves the reinforcement learning process. A primary motivation for future action influences positive feedback. Therefore, the more the positive feedback, more likely the person will be propelled to add to the community. Online reviews give an abundance of information to consumers. Nonetheless, every item or service that is provided online possibly attracts numerous reviews. Chevalier and Mayzlin (2006), for instance, noticed that the vendors and sellers possess motivations that assist in the supply of reviews or promotional chats to impact consumers' assessment of products and services. Queries constituting the authenticity are augmented by the feature that the interlinkages between customers take place in an online environment (Einwiller 2003). For instance, marketers have stimuli or incentives that, to impact consumers' product evaluation, supply promotional chat or reviews. Enhancing the understanding of Internet marketing dimensions is enhanced by psychological and social network theory.

\subsection{IMPACT OF ONLINE CUSTOMER REVIEWS ON CONSUMER BUYING BEHAVIOR}

\subsubsection{Impact on consumer attitude and purchase intentions:}

Numerous studies were carried out that highlighted the reviews of online customers. Huang and Chen (2006) explained how specific cues like customer feedback impact the product choices of the customers.

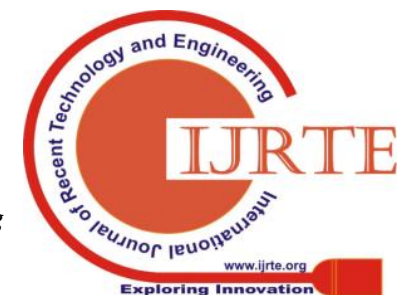


Later, research conducted by Jumin et al. (2008) investigated and inferred that the suggestions of different consumers impact the selection of subjects more successfully than proposed by an expert. Hu et al. (2008) analyzed online customer reviews. The researchers employed the portfolio approach for comprehending and validating the viability of online evaluations and reviews on consumers. They justified that the influence of online reviews decreases after a certain period of time. These observations potentially contributed to business strategies. Lee et al. (2006), however, had a slightly different perspective. They analyzed the impacts of negative consumer reviews online on consumer behaviour and discovered that the majority of obstructive reviews of customers online has the outcome of the conformity effect. They thus postulated that reviews that are negative, they influence the authentic purchasing behavior or the lease purchasing intention. Demangeot and Broderick (2006) suggest that consumers that prefer to buy online products or services are strongly recognized and connected with the traditional shopping action. Even though giving a wonderful online experience will impact customers', online shopping behavior, a large portion of the research centers exclusively on the manageable factors of the online experience.

\subsubsection{Impact on brand reputation:}

Many studies have been implemented to evaluate the efficacy of reliability of online history of customer feedback such as customer care, customer reviews, and online participation on consumer's brand choice for buying goods or services. A range of companies has understood that an all-around settled social online community platform can give exquisite advantages and a platform for market research (Libert \& Spector, 2007). They also suggested that it can create an economic department of creativity that is driven by customers and a ceaseless section of brand reliability. Wu and Sukoco (2010) established that the most crucial component propelling and impelling people to partake in an online brand community were an achievement. Muk and Chung (2014), for example, observed the factors that motivate the customers to follow the brand page. Christou (2015) in his conference paper, focused on understanding how brand loyalty can add to the customer's belief on social media. Christou (2015) likewise upheld on characteristics of the brand as key antecedents that predict the customer's faith. The dominant discoveries of Christou (2015) illustrated that consumer's faith could be estimated by the brands on social media. This adds up to a positive effect on brand loyalty.

\subsubsection{Impact of media influences:}

Organisations can have a tight and firm relationship with those customers by building and sustaining social ties among their customers and their brands. Coulter and Roggeveen, (2012), contributed by proposing that social media is generally acknowledged by global enterprises to improvise the customer's brand loyalty and to enhance customer experience. A majority of the researchers and scholars emphatically support social media as a guide to reinforce social media to assist in organizing their association with their aimed customers.. Moore et al. (2013) accords the function of social media in scaffolding the customers and making them adhere to their brands and implies that it could be accomplished by platforms such as Facebook or Twitter. Leeflang et al., (2014) states that most organisations have begun reasoning deliberately on the method by which they can earn profit from social media so that they get to their customers and add to their customer's experience. It is observed that even after purchasing the product by going through the reviews of other customers' experience and feedback on social media, customers tend to utilize social media for their future purchases (Drews and Schemer, 2010). In this review, the most widely recognized research approaches are embraced to analyze the associated concerns of marketing via social media.

\subsection{RESEARCH GAP}

The papers that are referred for the current study have mostly focused on the factors that urge the consumers to share their knowledge/information. However, very little or no conscious attention was paid on the factors that propel the customers to refer the online reviews for their buying decisions. It is essential to explore this circumstance of sharing information in online communities. Also, there has been scant research on the credibility of information based on internet, whether they have any influence and whether the consumer use and consumer opinions are affected by such reviews and internet based customer opinions. The recognized advantages, virtues and identified costs of involvement of consumers in e-commerce websites have been studied in the existing literature. Also, there is an insufficient theoretical explanation for a relationship between the contribution of customer reviews and social interactions online on online shopping platforms. Accordingly, the research gaps in the background studies are addressed with the aid of social cognitive learning theory to explain how online customer reviews affect the customer's purchase behaviors in online shopping platforms to understand the consumer's expectations and influence of media.

\section{FINDINGS AND DISCUSSION}

Ongoing improvements in social media have altogether altered how customers converse and trade product knowledge amongst themselves. The significant inferences drawn from the existing body of literature are presented to reach a conclusion. The outcomes of this study elucidate the impacts of online customer feedback and customer learning.

\subsection{Factors affecting consumer buying behavior:}

The conceptual framework summarizes the factors of online customer reviews among the investigations demonstrating which factors have been observed to affect the empirical literature. Individual factors, the empirical literature and the outcomes are discussed in detail below.

Conceptual framework: 


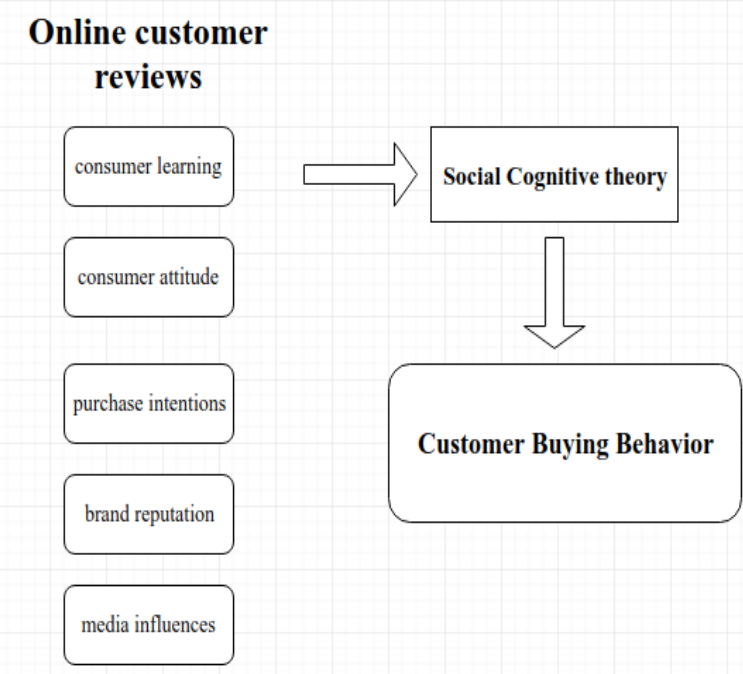

\section{Consumer learning:}

Jarvenpaa, Tractinsky, and Vitale (2000) investigated the way reputation and market size is recognized by consumers. They also investigated how it influences their belief in the market, comprehension of risks, their inclination towards buying products, and attitudes to purchasing at a particular marketplace. A direct efficacious relationship between consumer learning and the store's reputation was established by Jarvenpaa, Tractinsky, and Vitale (2000). Greater consumer loyalty and consumer belief has been seen to reduce perceived risks in regards to online purchases and causes positive consumer perception towards purchasing at a specific marketplace. This thus enhances the customer's eagerness to buy from that place. Also, Jahng, Jain, and Ramamurthy (2001) suggested a Technology Fit or a Product Fit Model understand and foresee the relevance and similarity among product characteristics, components of e-commerce environment, and the user findings. At the point, when an optimistic relationship is built up between the online market and product demands, desired outcomes are created that can be described and included as customer satisfaction, e-commerce acceptance, and purchase intent. Thus, this study identifies the positive relationship established between consumer learning and online selling of products.

\section{Consumer attitude:}

Consumer attitude of purchasing via e-commerce websites indicates the psychic state of consumers in terms of buying products online. Li \& Zang (2002) in their research, to explain the remarkable relationship between online reviews and customer buying behaviors, derived almost ten reticulated factors. These ten determinants are demographics, extraneous environment, individual attributes, seller/service/product traits, online shopping attitude, online purchasing intent, accountability, online shopping, and consumer contentment. Out of the ten, five, particularly, extraneous environment, statistics, individual attributes, seller/service/product traits, and quality of website are identified to be generally independent and other five, online shopping attitude, intent on shopping online, accountability, online shopping, and consumer contentment are usually dependent variables in the empirical literature.
The results of our review generally supported the research objectives. It was found that the consumer attitude is driven by a large number of factors listed above (Li \& Zang, 2002).

\section{Purchase intentions:}

Li \& Zang (2002) indicates to consumer's intention to purchase online as their potentiality to make purchases on e-commerce websites. Usually, this element is evaluated by consumer's ability to purchase, return and revert for extra purchases. Reverting for more purchases from the same store also adds to customer loyalty. Jarvenpaa et al., (2000) studied customers' aim to buy products through e-commerce websites by urging the customers to answer a series of questions that addressed the probability of purchasing from the same e-commerce website in the following three months again, the probability of buying within the following year, and the intent of purchasing from the same store ever. Findings of the study point towards the consumers' intention to purchase goods or services online are optimistically correlated with the attitude towards e-shopping and impacts their purchasing intent and shopping behavior. Moreover, there is proof of the required effect between online shopping intentions and customer satisfaction (Jarvenpaa et al., 2000). Most findings incorporate a more in-depth investigation of fundamental papers and articles explored in the present study. In conclusion, it leads to the observation of a variety of elements that are the highlight of consideration for preceding social media promotion and advertising studies (Mir, 2012; Jung et al., 2016; Kodjamanis and Angelopoulos, 2013; Lee et al., 2016; McCaughey et al., 2016).

\section{Brand reputation:}

The reputation of communities of online brand is potential tools for impacting sales, paying little heed to whether any company possesses these communities or independently possessed Websites. In addition to that, Adjei et al., (2010) recognised communities of the online brand as efficacious tools for retention of experienced as well as novice customers. This can be utilized as a guide to enhance the advertising and circulation of products on the web (Flavián and Guinalíu, 2005). Findings of the study explain the brand reputation is having an impact on the obstructions related to marketing via social media. The significant heterogeneity of literature that has tended to the relevant problems of marketing via social media demanded the significant consideration endowed for such occurrence over the ongoing years (Alalwan et al., 2016).

\section{Media influences:}

Social media is primarily considered as promising platforms by modern business to carry out promotional activities. Popp and Woratschek, (2016) suggested that it works towards successful interaction with the targeted customers. Bannister et al. (2013) explained that there are also some statistical factors of human populations such as gender and age on the interest of customers towards business enterprises and were carried out utilizing the platform of social media. 
Wang et al. (2012) observed that the use of social media mostly enhanced customers' involvement. Three key factors - entertainment, internal realization and recognition - were identified to be crucial predictors that aided in adding customers to exchange their ordeals and occurrences on social media. The research outcomes of the current study relate to Bolton et al. (2013), according to whom contemporary businesses and chairpersons must pay utmost contemplation to the behavior of novel generation and outlook towards the application of social media and customer participation in utilising these systems. Thus the proposed conceptual framework showcases these factors affecting the perceptions and attitudes of consumers regarding online reviews. With the help of social cognitive theory described above, how these factors affect the customer buying behavior is depicted.

\section{CONCLUSION}

The present study established that online consumer reviews unquestionably have a positive effect and an immediate association with consumer purchase behaviour. The research framework of this research enabled the reinforcement and likewise researched the antecedents and variables that impact consumer purchase intent. The perception of buyer about online media has an influence on consumer care and a substantial effect on the inclusion of customers in online activities. Shoppers who review items or services are very likely to impact customer care offered by organizations online. As a matter of fact, after the review of papers in this respect, it was discovered that the demographic factors did not affect shopper's decision to buy a specific brand. Another noteworthy indication is that social media still does not have confirmed measures as shown by Gao and Feng (2016). This could be the primary flaw in the assessment of customer perception and conduct toward promotions using online networking platforms. As a subset of the extensive e-marketing literature, shopper reviews and researches about social networking persists in being the transcendent hypothetical structure driving the present literature base. Moreover, online reviews of items have turned into a noteworthy informational hotspot for both, clients as well as the marketer. This investigation was restricted in terms of the number of variables that were presented with the assistance of a theoretical framework. Also, an absence of hypothetical structure to portray web-based shopping conduct and perceptions proposes the need to develop a model for advancing systematic examination of its components and the web-based shopping process. Future studies can draw from this research to examine the effect of demographics via web-based networking media and the decision of selecting a particular brand/organization. Future investigations could likewise investigate the distinctive consumer attributes like consumer experience influencing online social networks.

\section{CONFLICT OF INTEREST}

The authors confirm that there no conflict of interest to declare for this publication.

\section{ACKNOWLEDGEMENT}

The authors would like to acknowledge and thank the companies and managers who contributed to this research. Thank you for their support and time. The authors are also grateful to the colleagues who reviewed this paper and provided valuable suggestions towards improving it.

\section{REFERENCES}

1. Adjei, M., Noble, C. and Noble, S. (2010), "The influence of C2C communications in online brand communities on customer purchase behavior", Journal of the Academy of Marketing Science, Vol. 38 No. 5, pp. 634-653.

2. Alalwan, A., Rana, N., Algharabat, R. and Tarhini, A. (2016a). A Systematic Review of Extant Literature in Social Media in the Marketing Perspective. The 15th IFIP Conference on e-Business, e-Services and e-Society on Social Media: The Good, the Bad, and the Ugly, Swansea, UK.

3. Bandura, A. (1997). Self-efficacy: The exercise of control. New York: Freeman.

4. Bandura, A. (2001). Social cognitive theory of mass communication Media Psychology, 3(3), 265-299.

5. Bansal, H., and Voyer, P. Word-of-mouth processes within a services purchase decision context. Journal of Service Research, 3, 2, 2000, 166-178.

6. Bolton, R. N., Parasuraman, A., Hoefnagels, A., Migchels, N., Kabadayi, S., Gruber, T., ...\& Solnet, D. (2013).

7. Understanding Generation $Y$ and their use of social media: a review and research agenda. Journal of service management, 24(3), 245-267.

8. Case, T., Burns, O. M., and Dick, G. N. ìnivers of on-line purchasing among U.S. university students.î Proceedings of the 7th Americas Conference on Information Systems, 2001, pp. 873-878.

9. Centola, D. The spread of behavior in an online social network experiment. Science, 329, 2010, 1194-1197.

10. Chen, Y., Wang, Q., \& Xie, J. (2010). Online social interactions: A natural experiment on word of mouth versus observational learning. Available at SSRN 1501843.

11. Chen, Y.B., Wang, Q., \& Xie, J.H. (2011). Online social interactions: A natural experiment on word of mouth versus observational learning. Journal of Marketing Research, 48(2), 238-254.

12. Cheung, C.M.K., \& Lee, M.K.O. (2012). What drives consumers to spread electronic word of mouth in online consumer-opinion platforms. Decision Support Systems, 53(1), 218-225

13. Coulter, K.S., Roggeveen, A., 2012. "Like it or not” Consumer responses to word-of-mouth communication in on-line social networks. Manage. Res. Rev. 35 (9), 878-899.

14. Cui, G., Lui, H. K., \& Guo, X. (2012). The effect of online consumer reviews on new product sales. International Journal of Electronic Commerce, 17(1), 39-58.

15. Demangeot, C. and Broderick, A.J. (2006), "Exploring the experiential intensity of online shopping environments", Qualitative Market Research: An International Journal, Vol. 9 No. 4, pp. 325-351.

16. Drews, W., \& Schemer, C. (2010). eTourism for all? Online travel planning of disabled people. Information and Communication Technologies in Tourism 2010, 507-518.

17. Einwiller, $\mathrm{S}$. The significance of reputation and brand in creating trust between an online vendor and its customers. In

18. O. Petrovic, M. Fallenböck, and C. Kittl (eds.), Trust in the Network Economy, Springer-Verlag, Heidelberg, Germany, 2003, 113-127.

19. Ekelund, R., Mixon, F., and Ressler, R. Advertising and information: an empirical study of search, experience and credence goods. Journal of Economic Studies, 22, 2, 1995, 33-43.

20. Flavián, C. and Guinalíu, M. (2005), "The influence of virtual communities on distribution strategies in the internet", International Journal of Retail \& Distribution Management, Vol. 33 No. 6, pp. 405-425.

21. Gao, Q., \& Feng, C. (2016). Branding with social media: User gratifications, usage patterns, and brand message content strategies. Computers in Human Behavior, 63, 868-890.

22. Huang, J. and Chen, Y. (2006), "Herding in online product choice", Psychology and Marketing, Vol. 23 No. 5, pp. 413-28.

23. Jarvenpaa, S. L., Tractinsky, N., and Vitale, M. ìConsumer trust in an Internet store, î Information Technology and Management (1), 2000, pp. 45-71 
24. Jarvenpaa, S. L., Tractinsky, N., and Vitale, M. ìConsumer trust in an Internet store, Information Technology and Management (1), 2000, pp. $45 \tilde{n} 71$

25. Lee, J., Kim, S., and Ham, C. D. (2016). A Double-Edged Sword? Predicting Consumers' Attitudes Toward and Sharing Intention of Native Advertising on Social Media. American Behavioral Scientist, 0002764216660137.

26. Lee, J., Park, D. and Han, I. (2008), "The effect of negative online consumer reviews on product attitude: an information processing view", Electronic Commerce Research and Applications, Vol. 7 Nos 3, special section: New Research from the 2006 International, pp. 341-52.

27. Leeflang, P.S., Verhoef, P.C., Dahlström, P., Freundt, T., 2014 Challenges and solutions for marketing in a digital era. Eur. Manage. J. 32 (1), 1-12.

28. Li, N., \& Zhang, P. (2002). Consumer online shopping attitudes and behavior: An assessment of research. AMCIS 2002 Proceedings, 74.

29. Liang, T., and Lai, H. iElectronic store design and consumer choice: an empirical study,î Proceedings of the 33rd Hawaii International Conference on System Sciences, 2000.

30. Libert, B., \& Spector, J. (2007). We are smarter than me: How to unleash the power of crowds in your business. Upper Saddle River, NJ: Pearson Prentice Hall. 